\title{
Disseminated Herpes Zoster in the Immunocompetent, A Case at Zinder National Hospital
}

\author{
Mahamadou Doutchi, \\ Garba Abdoul-aziz, \\ Kassoumou Kadidia., \\ Health Sciences Faculty of Zinder University, \\ Zinder National Hospital, Niger \\ Moustapha M. Lamine, \\ Cheikh Anta Diop University of Dakar, Senegal \\ Harouna M. Laouali, \\ Health Sciences Faculty of Maradi University, Niger

\section{Alkassoum Ibrahim, Eric Adehossi, Salissou Danmata,} \\ Health Sciences Faculty of Abdou Moumouni University, Niamey, Niger
}

\section{Doi:10.19044/esj.2019.v15n36p528 URL:http://dx.doi.org/10.19044/esj.2019.v15n36p528}

\begin{abstract}
Introduction: Herpes zoster, shingles, is a secondary pathology due to a reactivation of the varicella-zoster virus (VZV) and common in the general population. It is responsible for a painful skin rash localized in the area of the body innervated by a nerve root. The rash can be widespread affecting several dermatomes especially in the immunocompromised subject. Observation: We report an observation of disseminated shingles in an immunocompetent adult hospitalized in the Internal Medicine Department of Zinder National Hospital. AT 55 years old, was admitted for management of a very painful skin rash. Pruriginous vesicles extended diffusely out of the metameric topography to all the enveloping membranes of the body including vulvo-vaginal and oral enanthem. Biologically, blood count (CBC), blood glucose, and renal function were normal. Human immunodeficiency virus (HIV) status was negative. The clinical course was uneventful characterized by apyrexia at 48 hours and drying of the lesions. Medical care was based on symptomatic treatment. Conclusion: Shingles is a common viral disease, but potentially serious in some situations. The disseminated form is exceptional in
\end{abstract}


the immunocompetent subject. Its detection and early treatment ensure a reduction in the severity of the complications.

Keywords: Disseminated Herpes Zoster, Immunocompetent, Widow

\section{Introduction}

Herpes zoster, shingles, is the clinical expression of reactivation of the varicella zoster virus (VZV). It is a DNA virus belonging to the herpesviridae family and of strictly inter-human transmission (1). Its incidence varies with age, from 3/1000 before the age of 30 to 8/1000 after age 60 (2-4). VZV infections are generally benign, but severe and disseminated forms are possible in immunocompromised individuals as well as in immunocompetent adults (1). The risk of disseminated shingles in subjects with malignant disease is 100 times higher than in healthy subjects (5). The clinical picture is that of a diffuse rash or even true chickenpox, much more often resurgences of previous infections than primary infections (6). Few authors have described disseminated shingles in the immunocompetent (2). We report a disseminated case of herpes zoster in an immunocompetent adult hospitalized at the Internal Medicine Department of Zinder National Hospital.

\section{Patient and method}

AT 55 years old, gravida 9, para 9, widowed 5 years previously, no significant pathological antecedents, especially childhood eruptive diseases and congenital or acquired immunodepression. The patient was admitted to internal medicine for management of a very painful skin rash in a context of intense physical asthenia, weight was $60 \mathrm{~kg}$, height $1.62 \mathrm{~m}$ or a BMI of $22 \mathrm{~kg} / \mathrm{m}^{2}$. The anamnesis revealed that symptoms began seven (7) days earlier with a tingling followed by the appearance of erythema accompanied by pain in the thoracolumbar hemi-belt region. Four (4) days later a vesicular exanthem appeared first in clusters then in confluent polycyclic blisters. These pruriginous vesicles extended diffusely out of the metameric topography (Fig 1 and 2) to all the enveloping membranes of the body including vulvo-vaginal and oral enantham. The diagnosis of generalized shingles was made on the basis of the singular nature of the lesions. Clinical examination elsewhere, specifically lymphatic and neurological, was without particularity.

Biologically, blood count (CBC), blood glucose, and renal function were normal. Human immunodeficiency virus (HIV) serology was negative. Medical care was based on symptomatic treatment with analgesics (paracetamol 1 gram 3 times a day and tramadol 100mg three times a day), antihistamines (hydroxizine $25 \mathrm{mg}$ per day), antiseptics (aqueous Eosin 2\% two daily applications) and antiviral treatment based on oral acyclovir (10 $\mathrm{mg}$ per kg every 8 hours). The clinical course was favourable; characterized by 
apyrexia after 48 hours and the drying of lesions with crust formation within seven days.

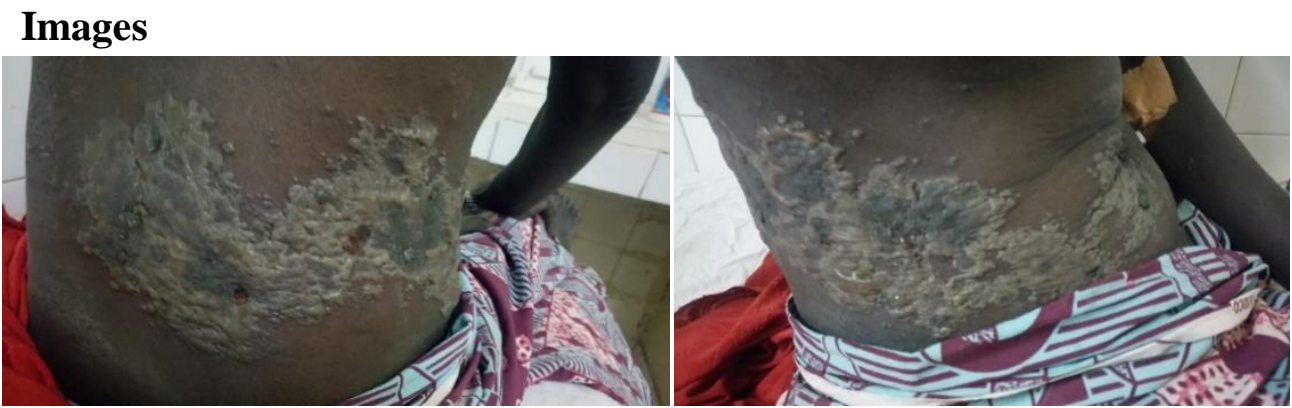

Figure 1: Band of disseminated rash on the abdomen and back.

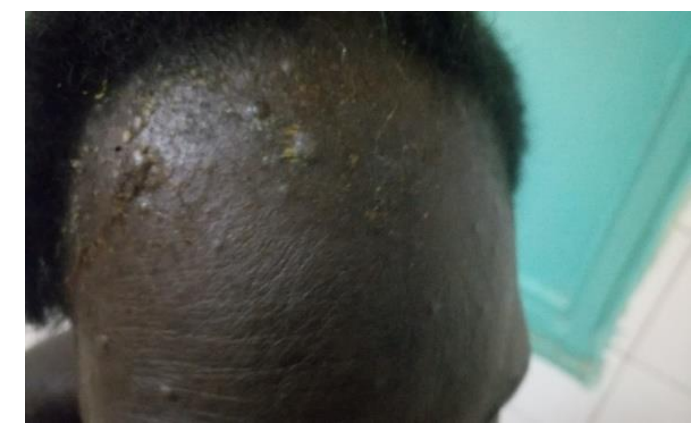

Figure 2: Vesicular rash on the forehead and scalp

\section{Discussion}

The VZV seroprevalence in the general population is extremely high, around $98 \%$ in adults (1). Incidence increases from $3 / 1000$ before 30 years to more than $8 / 1000$ after 30 years (2). The occurrence of chicken pox before one year of age is a predisposition to the onset of shingles before the age of 60 (7). Risk factors that may trigger or aggravate shingles are: age, immunodeficiency, diabetes, stress (8). Our patient was 55 years old. In the Gargouri series, out of 115 patients followed for shingles from 2005 to 2015 at the Sfax infectious diseases department in Tunisia, the mean age was $56 \pm$ 17 years (9). Beyond her age, the only other risk factor cited in the literature found in our patient was stress. In fact, our patient had lost her husband and had a hard time providing for her family. Stress, especially in the 6 months preceding shingles, may have a role in promoting the reactivation of VZV by altering the cellular immunity of subjects (10). Our patient's immunosuppression assessment was not exhaustive due to the technical limitations of our laboratory. It included a blood count, liver and kidney biology report, HIV serology, neoplastic and diabetic status, and an assessment of nutritional status. Complementary measures, plasma protein electrophoresis, and specific immunoglobulin assays were not performed. 
Clinically after a silent 14-day incubation, the invasion phase is short (24 hours), characterized by a febrile prodromal syndrome with discomfort (1). The usual clinical presentation begins with an abnormal skin sensation, then pain of varying intensity (respecting a dermatome) preceding a rash of 1 to 5 days. The erythematous-maculopapular rash is followed by the formation of vesicles evolving towards ulceration then the formation of crusts. The dermatome area may be exceeded in $20 \%$ of cases. Observations of simultaneous involvement of several dermatomes have been reported but never in immunocompetent individuals (8). This reflects the singularity of our observation. Indeed, in our patient we observed a diffuse alveolar vesicular rash outside the metameric topography (Fig 1 and 2) to all the enveloping membranes of the body including vulvo-vaginal and oral enantham. A true "varicella -zoster" (Fig. 1, 2).

Therapeutically, the recommended regimens for the immunocompetent subject are: oral valacyclovir, 3 doses of $1 \mathrm{~g} /$ day for 7 days; oral famciclovir, 3 doses of 500 to $750 \mathrm{mg} /$ day for 7 days $(11,12)$; with 3 doses of $500 \mathrm{mg} /$ day advised. There is no benefit in extending the duration of treatment beyond 7 days. The addition of a corticosteroid does not increase the effectiveness of the antiviral drug (13). Studies have shown that these antivirals, compared to placebo, can shorten the duration of the acute episode, limit the appearance of new lesions, accelerate recovery and reduce acute pain. (14). In addition, a meta-analysis showed that acyclovir was significantly superior to placebo in reducing the duration of zoster pain (15). Tricyclic antidepressants are of major interest in the treatment of post-herpetic neuralgia. Of these, amitriptyline has been the most studied; taken orally, at a dosage ranging from 10 to $150 \mathrm{mg} /$ day, it has a proven efficacy after 3 to 6 weeks (16). Our patient was treated with acyclovir and the clinical course was favourable characterized by apyrexia at 48 hours and dryness of the lesions with formation of crusts within 7 days.

The introduction of the VZV vaccine and especially the recommendation of a second injection to prolong the induced immunity should help reduce the incidence of shingles in the population $(17,18)$. Immunization efficiency is estimated at $85 \%$ according to the special issue of the Journal of Infectious Disease (19) which completes the 2007 article of the New England Journal of Medicine (17) presenting the results of the first ten years of this vaccine in the USA. The VZV vaccine is not yet in the Expanded Program on Immunization in Niger and would be a good alternative to prevent shingles in the country.

\section{Conclusion}

Shingles is a common viral disease, but potentially serious in some situations. The disseminated form is exceptional in the immunocompetent 
subject. Its detection and early treatment ensures a reduction in the severity of the complications.

\section{References:}

1. Freer G, Pistello M. Varicella-zoster virus infection: natural history, clinical manifestations, immunity and current and future vaccination strategies. New Microbiol. 2018;41(2):95-105.

2. Tran CT, Ducancelle A, Masson C, Lunel-Fabiani F. Herpes zoster: risk and prevention during immunomodulating therapy. Joint Bone Spine. 2017;84(1):21-27.

3. Pappas DA, Hooper MM, Kremer JM, Reed G, Shan Y, Wenkert D, et al. Herpes zoster reactivation in patients with rheumatoid arthritis: analysis of disease characteristics and disease-modifying antirheumatic drugs. Arthritis Care Res. 2015;67(12):1671-1678.

4. Yun H, Yang S, Chen L, Xie F, Winthrop KL, Baddley J, et al. herpes Zoster Infection Risk in Auto-immune and Inflammatory Diseases: Implications for Vaccination.: 820. Arthritis Rheumatol. 2014;66:S360-S361.

5. Banerjee A. Zona de l'enfant. Arch Pédiatrie. févr 1998;5(2):199 203.

6. Nedellec G, Bauduceau O, Amadou S, Foissaud V, Souleau B, Galoo $\mathrm{E}$, et al. Syndrome douloureux abdominal précédant un zona généralisé chez un immunodéprimé. Médecine Mal Infect. 1 juill 2003;33(7):353 5.

7. Guess HA, Broughton DD, Melton LJ, Kurland LT. Epidemiology of herpes zoster in children and adolescents: a population-based study. Pediatrics. 1985;76(4):512-517.

8. Mathis S, Gil R, Neau JP. Le zona et ses complications neurologiques. Rev Neurol (Paris). 2006;162(8 9):879-887.

9. Gargouri M, Koubaa M, smaoui F, Mejdoub Y, Hakim D, Tlijani A, et al. VIRO-04 - Le zona: quand le virus de varicelle refait surface. Médecine Mal Infect. 1 juin 2016;46(4, Supplement 1):129.

10. Schmader KE, Dworkin RH. Natural history and treatment of herpes zoster. J Pain. 2008;9(1):3-9.

11. Degreef H. Famciclovir Herpes Zoster Clinical Study Group: Famciclovir, a new oral antiherpes drug: Results of the first controlled clinical study demonstrating its efficacy and safety in the treatment of uncomplicated herpes zoster in immunocompetent patients. Int $\mathbf{J}$ Antimicrob Agents. 1994;4:241-246.

12. Boon RJ, Griffin DR. Efficacy of famciclovir in the treatment of herpes zoster Reduction of pain associated with zoster. Neurology. 1995;45(12 Suppl 8):S76-S77. 
13. Beutner KR, Friedman DJ, Forszpaniak C, Andersen PL, Wood MJ. Valaciclovir compared with acyclovir for improved therapy for herpes zoster in immunocompetent adults. Antimicrob Agents Chemother. 1995;39(7):1546-1553.

14. Huff JC, Bean B, Balfour JH, Laskin OL, Connor JD, Corey L, et al. Therapy of herpes zoster with oral acyclovir. Am J Med. 1988;85(2A):84-89.

15. Wood MJ, Kay R, Dworkin RH, Soong S-J, Whitley RJ. Oral acyclovir therapy accelerates pain resolution in patients with herpes zoster: a meta-analysis of placebo-controlled trials. Clin Infect Dis. 1996;22(2):341-347.

16. Zhang M, et al. A meta-analysis of therapeutic efficacy and safety of gabapentin in the treatment of postherpetic neuralgia from randomized controlled trials. Biomed Res Int. 2018;2018:7474207.

17. Gagliardi, A. M., Andriolo, B. N., Torloni, M. R., Soares, B. G., de Oliveira Gomes, J., Andriolo, R. B., \& Canteiro Cruz, E. (2019). Vaccines for preventing herpes zoster in older adults. Cochrane Database of Systematic Reviews. doi:10.1002/14651858.cd008858.pub4

18. Guris D, Jumaan AO, Mascola L, Watson BM, Zhang JX, Chaves SS, et al. Changing varicella epidemiology in active surveillance sitesUnited States, 1995-2005. J Infect Dis. 2008;197(Supplement_2):S71-S75.

19. CDC Varicella Vaccine Recommendations. https ://www. cdc.gov/vacci nes/vpd/varic ella/hcp/recom menda tions .html. Accessed 28 Aug 2019. 